\title{
Systems pharmacology and transcriptomics reveal the mechanisms of Sanhuang decoction enema in the treatment of ulcerative colitis with additional Candida albicans infection
}

\author{
Zhijun Han $^{1 \dagger}$, Xiaofen Tan ${ }^{1 \dagger}$, Juan Sun ${ }^{3,4}$, Tianming Wang ${ }^{1,2,3,4}$, Guiming Yan 1,2,3,4 , Changzhong Wang 1,2,3,4 and
} Kelong $\mathrm{Ma}^{1,2,3,4^{*}}$

\begin{abstract}
Background: Ulcerative colitis (UC) is an important inflammatory phenotype in bowel disease (IBD), which is caused by multiple potential factors, including fungal dysbiosis. Candida albicans (C. albicans) was confirmed to be an important factor promoting the occurrence and development of UC. Sanhuang decoction (SHD) has been used for UC therapy in China for thousand of years, although its core active constituents and pharmacological mechanism remain undefined.

Methods: In this work, a murine model of UC with C. albicans colonization was established with dextran sodium sulfate (DSS) and C. albicans intragastric administration. The major bioactive constituents and potential mechanism of SHD against UC with fungal dysbiosis were comprehensively examined by combining systems pharmacology and in vivo transcriptomics.

Results: SHD attenuated C. albicans burden, reduced DAl, increased mucosal integrity and relived systemic inflammation in UC mice. Systems pharmacology analysis identified 9 core bioactive ingredients and 45 hub targets of SHD against UC. Transcriptomics analysis confirmed 370 differentially expressed genes (DEGs) after SHD treatment, which were mainly enriched in inflammatory and immune response related signaling pathways. Toll-like receptor and PI3KAkt signaling pathway were screened out as the candidate targets involved in the action of SHD on fungal dysbiosisassociated UC, which were consistent with the findings in systems pharmacology. The expression of TLR4, IL-1 $\beta, N F-K B$, PI3K and Akt proteins were stimulated by C. albicans, and partially reversed by SHD in UC mice.
\end{abstract}

Conclusion: These findings suggested SHD could be a candidate for the treatment of fungal dysbiosis-associated UC via TLR4-NF-KB and PI3K-Akt signaling pathways.

Keywords: Ulcerative colitis, Candida albicans, Sanhuang decoction, Systems pharmacology, Transcriptomics

*Correspondence: mkl@ahtcm.edu.cn

${ }^{\dagger}$ Zhijun Han and Xiaofen Tan contribute equally to this paper

${ }^{1}$ College of Integrated Chinese and Western Medicine, College of Life Science, Anhui University of Chinese Medicine, Hefei 230012, China

Full list of author information is available at the end of the article

\section{Background}

Ulcerative colitis (UC) represents an important chronic inflammatory disease of the gastrointestinal (GI) tract featuring abdominal pain, diarrhea and rectal bleeding, with a significant impact on the quality of life [1]. Recently, the incidence and prevalence of UC have significantly increased in underdeveloped regions such as Asia original author(s) and the source, provide a link to the Creative Commons licence, and indicate if changes were made. The images or other third party material in this article are included in the article's Creative Commons licence, unless indicated otherwise in a credit line to the material. If material is not included in the article's Creative Commons licence and your intended use is not permitted by statutory regulation or exceeds the permitted use, you will need to obtain permission directly from the copyright holder. To view a copy of this licence, visit http://creativecommons.org/licenses/by/4.0/. The Creative Commons Public Domain Dedication waiver (http://creativeco mmons.org/publicdomain/zero/1.0/) applies to the data made available in this article, unless otherwise stated in a credit line to the data. 
and Africa, especially in China, where it was previously thought to be uncommon [2-4]. The pathogenesis of UC is complex, and several factors including genetics, environmental stimuli, immune disorder and the gut microbiota are considered to be involved in the occurrence and development of UC.

Fungi have long been suspected in UC pathogenesis, although they account for only $0.1 \%$ of the whole gut microbiota in healthy individuals [5]. Currently, growing evidence reveals that fungi are critical in maintaining intestinal homeostasis and the balance of immune response [6]. Several lines of evidence suggest that intestinal inflammation induces fungal proliferation [7]; on the other hand, certain fungal organisms modulate susceptibility to inflammation $[7,8]$. C. albicans $(\mathrm{Ca})$, one of the most common opportunistic fungi in the human GI tract, is thought to be associated with UC development. Several reports showed that UC patients have excessive C. albicans load in the GI tract, and antifungal drugs can alleviate UC [5, 9-11]. In addition, C. albicans administration aggravates dextran sulfate sodium-induced colitis in the mouse model, with higher inflammatory cytokine secretion levels and severer mucosal damage [12, 13].

San-Huang Decoction (SHD), also known as SanHuang-Xie-Xin-Tang, is a classical traditional Chinese herbal formula, firstly recorded in the Synopsis of Prescriptions of the Golden Chamber written 2000 years ago. SHD consists of Coptidis Rhizoma (CR, Huanglian in Chinese), Scutellariae Radix (SR, Huangqin in Chinese) and Radix Rhei Et Rhizome (RR, Dahuang in Chinese), is traditionally used to clear damp-heat, remove blood stasis and detoxification. Emerging evidence shows that SHD can prevent cell apoptosis [14], suppress viral replication [15] and alleviate inflammation [16]. In addition, active compounds from SHD, e.g., berberine [17-19], baicalin [20-22] and emodin [23], have functions of anti$\mathrm{UC}$ and modification of the gut microbiota components such as C. albicans. Previous studies revealed that SHD is broadly utilized in China for treating UC due to its synergistic and reliable effects [24, 25]. However, the major constituents and detailed mechanism of SHD in the treatment of C. albicans-associated UC remain unclear and need to be fully elucidated.

In the present study, we aimed to explore the potential role and underlying mechanism of SHD enema in UC with C. albicans dysbiosis. Mice with DSS-induced $\mathrm{UC}$ and $C$. albicans colonization were examined. The therapeutic effects of SHD were assessed by determining fungal burden, weight loss, DAI, histological score and serum contents of inflammatory factors. Systems pharmacology and transcriptomics were utilized to elucidate the molecular mechanisms of SHD in the treatment of UC involving C. albicans-associated dysbiosis. Post SHD treatment, the fecal fungal burden was reduced, and mucosal damage and systemic inflammation were alleviated. The PI3K-Akt and Toll like receptor signaling pathways were identified as SHD targets in treating the disorder. These findings provide novel insights in the mechanisms of SHD in the treatment of $C$. albicans-associated UC.

\section{Methods}

\section{Animals and strains}

Sixty specific pathogen-free (SPF) Kunming mice (female, $6 \sim 8$ weeks, $20 \pm 5 \mathrm{~g}$ ) provided by Anhui Medical University Experimental Animal Center (Hefei, China, license No. SCXK Anhui 20170001) were housed at $18 \sim 25{ }^{\circ} \mathrm{C}$ and $50 \sim 70 \%$ relative humidity, under a $12 \mathrm{~h}$ light-dark cycle. Experiments involving animals had approval from the Animal Ethics Committee of Anhui University of Chinese Medicine.

C. albicans SC5314 was kindly provided by Professor Yuanying Jiang (Naval Medical University, Shanghai, China). Routine isolation and culture were performed as previously described [6].

\section{SHD preparation and quality control}

Coptidis Rhizoma (CR), Scutellariae Radix (SR) and Radix Rhei Et Rhizome (RR) were purchased from Anhui Hospital of Chinese Medicine (Hefei, China). SHD enema was prepared as previously reported [24, 25]. The drugs were mixed at a ratio of 1:1:1 and extracted with $2 \mathrm{~L}$ of distilled water for $30 \mathrm{~min}$. Then, the extract was boiled for $40 \mathrm{~min}$. The cooled aqueous solution underwent centrifugation at $5000 \times g$, collecting the supernatant, which underwent filtration through a $0.45 \mu \mathrm{m}$ sterile microporous membrane. The filtrate was concentrated to $1.25 \mathrm{~g} / \mathrm{mL}$ for further use. According to the requirement standards of the Pharmacopoeia of the People's Republic of China (2020 edition), the contents of berberine, palmatine, baicalin, rhein and emodin in SHD were detected by liquid chromatography-mass spectrometry (LC-MS). The conditions were as follow: an Agilent C18 $(2.1 \mathrm{~mm} \times 100 \mathrm{~mm}, 1.8 \mu \mathrm{m})$ with solvent A: $0.1 \%$ formic acid and solvent $\mathrm{B}$ : gradient methanol elution was used in the LC-MS detection system (1290-6460, Agilent, USA). The solvent flow rate was $0.3 \mathrm{~mL} / \mathrm{min}$ in a column, at $40{ }^{\circ} \mathrm{C}$. Berberine, palmatine and baicalin were performed on ESI + ionization modes, rhein and emodin were on ESI - ionization modes with data acquisition range from 10 to $500 \mathrm{Da}$. The measurements were done in triplicate samples, and the results were listed in Additional file 1: Fig. S1 and Additional file 2: Table S1. 


\section{Animal model establishment and drug treatment}

The animal model was established according to previous studies [6,9]. In brief, mice were orally administrated $3.0 \%(\mathrm{w} / \mathrm{v}$ ) dextran sulfate sodium (DSS, 36-50 kDa, MP Biomedicals) for consecutive 7 days. The animals with bloody or loose feces, with or without $>3 \mathrm{~g}$ body weight reduction at any time point were considered to have colitis. Then, the animals were randomized into 5 groups of 10 each, including the DSS, Model (DSS + Ca), SHD low dosage (SHD-L, $3.75 \mathrm{~g} / \mathrm{kg}$ ), SHD high dosage (SHD-H, $15.00 \mathrm{~g} / \mathrm{kg}$ ) and sulphasalazine (SASP, $0.72 \mathrm{~g} / \mathrm{kg}$ ) groups. In the Model group, mice were intragastrically administrated $1.0 \times 10^{8}$ live C. albicans SC5314 for 4 days. In the SHD low and high groups, mice were subsequently treated with $3.75 \mathrm{~g} / \mathrm{kg}$ and $15.00 \mathrm{~g} / \mathrm{kg}$ SHD enema once daily for 7 days, respectively. Mice in the SASP group were given $0.72 \mathrm{~g} / \mathrm{kg}$ SASP. Mice in the Control and Model groups were administered the same amount of saline. The administration of enema was performed as follows: mouse was fixed and faced upward to expose the anus. A enema syringe attached with a polyethylene catheter (outer diameter $2 \mathrm{~mm}$ ) was inserted about $4 \mathrm{~cm}$ into the mouse rectum, the anus was squeezed, and $0.3 \mathrm{~mL}$ enema solution was slowly injected into the rectum for $30 \mathrm{~s}$ to $1 \mathrm{~min}$, then the mouse was held upside down for $1 \mathrm{~min}$ to retain the enema solution. During this process, the enema solution was maintained at $37{ }^{\circ} \mathrm{C}$, and all the instruments were treated aseptically. After mice were anesthetized with pentobarbital sodium $(50 \mathrm{mg} / \mathrm{kg}$, intraperitoneally), blood samples were collected by removing the left eyeball of the mice, and serum samples were kept at $-20{ }^{\circ} \mathrm{C}$. Mice were sacrificed by cervical dislocation. Colons were excised and measured for length. Then, colon specimens were fixed with formalin or stored at $-80^{\circ} \mathrm{C}$ until use. The disease activity index (DAI) of each mouse was calculated daily, consisting of body weight loss (0, no loss; $1,0-5 \% ; 2,5-10 \% ; 3,10-20 \%$; 4 , > 20\%), stool consistency ( 0 , normal; 2, loose stool; 4, diarrhea), and fecal blood (0, normal; 2, hemoccult; 4 , gross bleeding) [26].

\section{Candida albicans burden assessment}

Candida albicans amounts in the GIT were examined by plate counting after culturing fecal samples obtained from every mouse as described in our previous study [6]. Fecal specimens were weighed, resuspended in PBS and plated on Sabouraud dextrose agar supplemented with
Komaga (No. K08A, Bio-engineering, Shanghai, China) for $48 \mathrm{~h}$ of culture at $37{ }^{\circ} \mathrm{C}$. Yeast colonies were then counted, and expressed as CFU/10 mg feces.

\section{Detection of ASCA and $\beta$-glucan}

Mouse serum samples were obtained, and the contents of ASCA (CK-E22252, Ruixin Biotech., Fujian, China) and $\beta$-glucan (F30161-B, Kexing Biotech., Shanghai, China) were assessed with ELISA kits as directed by the manufacturer.

\section{Histopathological analysis}

Colon tissues were dissected and fixed with formalin, dehydrated, paraffin embedded and sectioned at $4 \mu \mathrm{m}$ for hematoxylin and eosin (H\&E) staining. Imaging and analysis were performed with a BX51 microscope (Olympus, Japan). The histopathological score was determined according to a previously published method [13].

\section{Serum TNF- $\alpha$, IL-1 $\beta$, IL- 6 and IL-10 level evaluation}

Serum was isolated by centrifugation of blood samples at $5000 \mathrm{rpm}$ for $10 \mathrm{~min}$. ELISA kits (MLBIO Biotechnology Co. Ltd. Shanghai, China) were utilized for determining the serum contents of TNF- $\alpha$ (ml002095), IL-1 $\beta$ (ml063132), IL-6 (ml002283) and IL-10 (ml002294).

\section{Systems pharmacology analysis Screening of chemical components and prediction of related targets in SHD}

The chemical ingredients of SHD were screened from the TCMSP (http://www.tcmspw.com/tcmsp.php) and TCMID (http://www.megabionet.org/tcmid/) databases. Ingredients meeting the demands of oral bioavailability $(\mathrm{OB}) \geq 30 \%$ and drug-like property $(\mathrm{DL}) \geq 0.18$ were selected for identifying effective constituents. The potential targets of these compounds were screened in SwissTargetPrediction (http://www.swisstargetprediction. ch) based on SMILES strings which were obtained from PubChem (https://pubchem.ncbi.nlm.nih.gov/). The official name of each target gene was standardized based on the UniProtKB database (https://www.uniprot.org/).

(See figure on next page.)

Fig. 1 SHD attenuates the development of DSS colitis with C. albicans. A Experimental design of C. albicans administration in mice with colitis and SHD treatment. B Body weights. C Disease active index values. D Colon lengths. E Histological scores. F Colonic tissue samples after H\&E staining ( $\times 200)$. Data are mean \pm SD. ${ }^{\#} P<0.05,{ }^{\# \#} P<0.01$ versus normal group; ${ }^{*} P<0.05,{ }^{* *} P<0.01$ versus Model group 


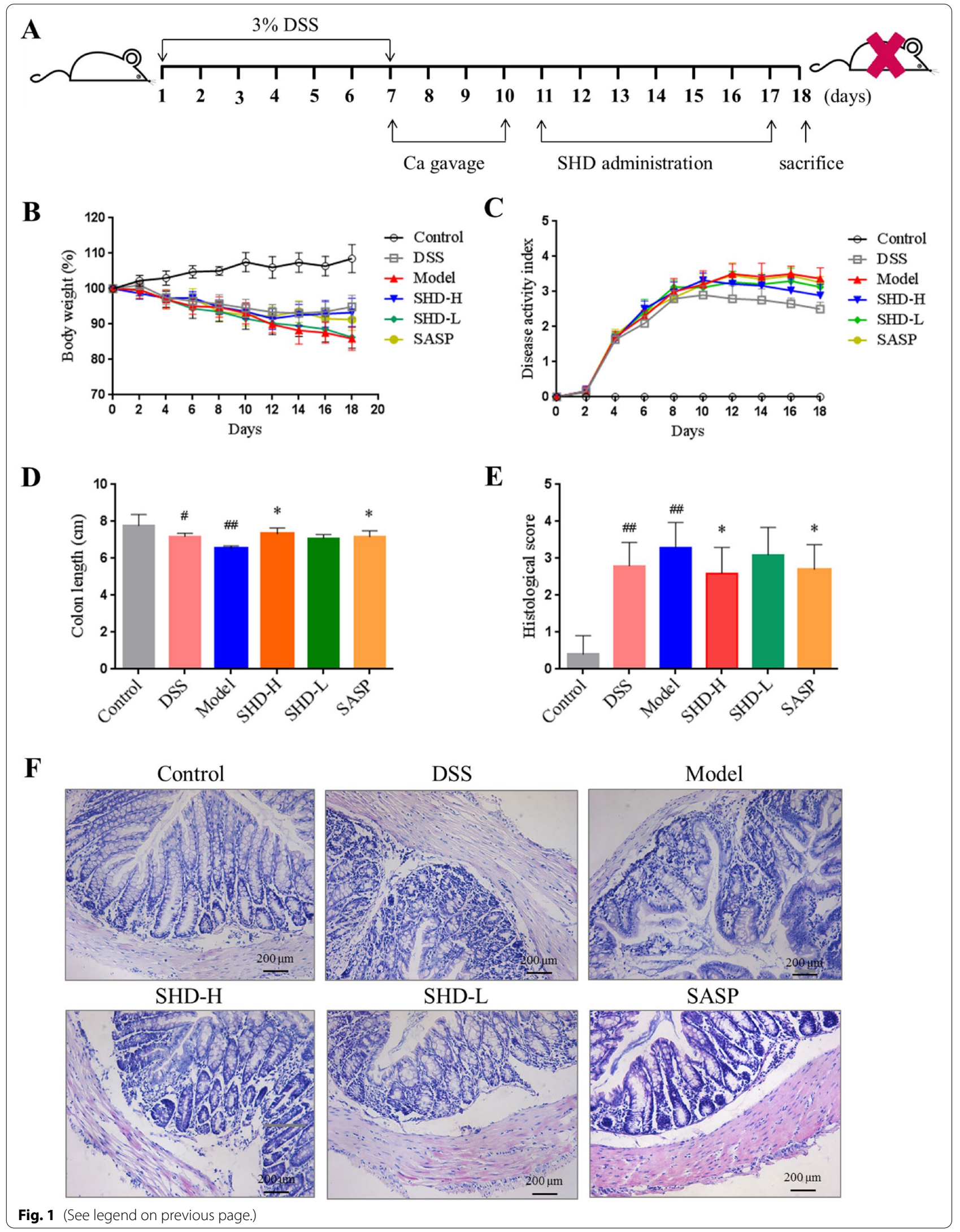




\section{Identification of ulcerative colitis-related targets}

Ulcerative colitis related genes were searched and collected using the DisGeNET (http://www.disgenet.org) and GeneCards (https://www.genecards.org) databases with the keyword "ulcerative colitis, UC". Repeated genes were discarded.

\section{Protein-protein interactions and compound-target network building}

Potential SHD's therapeutic targets in UC were molecules simultaneously targeted by SHD constituents and UC. The STRING database (https://string-db.org/) was utilized for building a protein-protein interaction (PPI) network for these common targets. Cytoscape 3.7.1 (https:// www.cytoscape.org/) was used to analyze the generated network. The final major targets of SHD in UC were selected based on Degree Centrality (DC), Betweenness Centrality (BC) and Closeness Centrality (CC), which are the mainly three categories of centrality in network analysis, accroding to network pharmacology evaluation method guidance [27]. Cytoscape was utilized to build a network of these main targets.

\section{Gene ontology (GO) and Kyoto Encyclopedia of Genes and Genomes (KEGG) pathway enrichment analyses}

GO and KEGG pathway enrichment analyses of key targets utilized the DAVID system (https://david.ncifcrf. gov/, v6.8) and R package. $P<0.05$ was considered statistically significant.

\section{Transcriptomic analysis}

Total RNA from colonic tissue samples in the Control, Model and SHD-H groups was isolated, enriched and purified with oligo-dT magnetic beads. Then, cDNA was synthesized, primed with poly-A and connected with sequencing adapters. Next, cDNA library construction and RNA sequencing were performed by Beijing Genomics Institution (Shenzheng, China). Clean reads were obtained with the SOAP nuke software by removing low quality reads from raw reads, and mapped to the reference genome (GCF_000001635.26_GRCm38.p6) by Bowtie2. Differentially expressed genes (DEGs) were obtained by the DEseq2 method according to the negative binomial distribution principle. The screening criteria for DEGs were FDR (false discovery rate) $<0.05$ and $\log 2 \mid \mathrm{FC}$ $1 \geq 2$.

\section{Western blot}

Total protein from colonic tissue specimens was isolated and resolved by SDS-PAGE. After transfer onto PVDF membranes, 5\% skimmed milk was utilized for blocking. The blocked membranes underwent incubation with anti-TLR4 (AF7017, 1:1000), anti-NF-kB
(AF5006, 1:1000), anti-p-NF-kB (AF2006, 1:1000), antiPI3K (AF6241, 1:1000), anti-p-PI3K (AF3241, 1:1000), anti-Akt (AF6261, 1:500), anti-p-Akt (AF0016, 1:500), anti-IL-1 $\beta$ (AF5103, 1:1000) and anti- $\beta$-actin (AF5332, 1:1000) primary antibodies from Affinity Bioscience (Cincinnati, OH, USA) overnight, respectively. Then, the membranes were incubated with horseradish peroxidaselinked secondary antibodies (E-AB-1003; Elabscience, Wuhan, China). Signals were detected with an ECL imaging system (LAS4000, GE, Pittsburgh, PA, USA). ImageJ (National Institutes of Health, Bethesda, Maryland, USA) was used for quantitation.

\section{Immunohistochemistry}

Colonic tissue sections underwent deparaffinization, rehydration and washing with PBS. Upon blocking with $10 \%$ goat serum, the sections underwent successive incubations with primary (overnight, $4{ }^{\circ} \mathrm{C}$ ) and secondary (ambient, $1 \mathrm{~h}$ ) antibodies. Then, diaminobenzidine was added as well as hematoxylin for counterstaining. A BX51 microscope was utilized for imaging at $200 \times$.

\section{Statistical analysis}

Data are mean $\pm S D$, and were compared by one-way analysis of variance (ANOVA) with post hoc Tukey's or student's $t$-test. SPSS 22.0 (SPSS, Chicago, IL, USA) was used for data analysis. $P<0.05$ indicated statistical significance.

\section{Results}

SHD exhibits therapeutic effects in mice with DSS colitis administered C. albicans

A C. albicans colonized-UC animal model was established and described in Fig. 1A. C. albicans overtly aggravated $\mathrm{UC}$ as indicated by more pronounced body weight loss, elevated DAI and histological score, reduced colon length and more severe colonic epithelial mucosa damage compared with the DSS group (Fig. 1B-F, Additional file 1: Figure S2). These changes were mitigated after SHD administration. Compared with the Model group, body weight loss was reduced and DAI was decreased in the SHD groups (Fig. 1B, C). Besides, colon lengths were increased while histological scores were lower in the SHD-H group compared with the Model group (both $P<0.05$ ) (Fig. 1D, E), suggesting that SHD-H had better effects than SHD-L.

\section{SHD reduces fungal burden and systemic inflammation in UC mice}

C. albicans is not a commensal fungi in mice (36), and the mouse model of DSS colitis with $C$. albicans infection may highly mimic the human condition (additional C. albicans). Indeed, there was no $C$. albicans isolated 
from fecal samples in the Control and DSS alone groups. However, in the Model group, fecal C. albicans quantities were above $5 \times 10^{5} \mathrm{CFU} / 10 \mathrm{mg}$ at day 11 after gavage with $C$. albicans for 4 consecutive days (Fig. 2A). In addition, as shown in Fig. $2 \mathrm{~B}, \mathrm{C}$, serum amounts of $\beta$-glucan (an important marker of fungal infection) and serum ASCA (an indicator of IBD) were increased in the Model group in comparison with the DSS and Control groups, implying aggravated systemic inflammation by $C$. albicans administration $(P<0.01)$. SHD had a certain anti- $C$. albicans effect in vivo. Compared with the Model group, the amounts of $C$. albicans were obviously decreased in the SHD-H group at days 12 and 13 (Fig. 2A). Moreover, serum $\beta$-glucan levels overtly decreased in the SHD-H group compared with the Model group $(P<0.05)$, while serum ASAC had no change among treatment groups.

Consistent with the aforementioned results, C. albicans inoculation worsened inflammation in mice with DSS colitis as indicated by higher serum amounts of TNF- $\alpha$, IL- $1 \beta$ and IL- 6 (proinflammatory cytokines) and lower levels of IL-10 (anti-inflammatory cytokine), compared with the DSS alone group (Fig. 2D-G). SHD effectively attenuated the systemic inflammation, as serum amounts of TNF- $\alpha$, IL- $1 \beta$ and IL- 6 were reduced while IL- 10 levels were elevated in the SHD-H group in comparison with the Model group $(P<0.05$ or 0.01$)$ (Fig. 2D-G).

\section{Active components of SHD}

To decipher the underlying mechanism of action of SHD in UC treatment, we screened potential active compounds using a well-established in silico ADME pipeline. We obtained 283 candidate compounds (48 CR, 143 SR and $92 \mathrm{RR}$ ) from the TCMSP database, and determined their corresponding ADME parameters, including $\mathrm{OB}$ and DL. Of these constituents, 66 (14 CR, 36 SR and 16 $R R)$ passed the drug screening criteria $(O B \geq 30 \%$ and $\mathrm{DL} \geq 0.18$ ), and were retained for further processing. The potential active constituents and respective targets in SHD are listed in Table 1. Of these targets, quercetin had 154 targets, making it the compound with the most targets in SHD, followed by wogonin (45 targets) and betasitosterol (38 targets).

\section{Core compounds screening and hub target network construction}

Swiss Target Prediction and the TCMSP database were utilized to identify compound-related targets, and the compound-target network was built with Cytoscape. Post discarding the compounds with no predicted target, we obtained 11 active constituents with 182 predicted targets in CR, 32 active compounds with 122 targets in SR, and 10 active constituents with predicted 71 targets in RR, totaling 342 non-redundant targets in SHD (Fig. 3A, Table 1). The UC-related target genes were screened using GeneCards and DisGeNet databases, finally yielding 1984 UC-related targets. Then, the targets of SHD were matched with those of UC, and a total of 87 SHD-UC targets were determined (Fig. 3B).

To further explore the detailed functions of the 87 SHD-UC targets, a protein-protein interaction analysis was conducted with an online tool, the STRING database. A network comprising 87 targets was built, with 1602 edges (medium confidence score $>0.4$ ). The core network, comprising 45 nodes and 838 edges, was generated based on DC above median value (37), $\mathrm{BC} \geq$ median $\mathrm{BC}$ value (0.003) and $\mathrm{CC}$ value $\geq$ median $\mathrm{CC}(0.64)$ in topological network analysis (Fig. 3C). These 45 hub genes were mainly regulated by 9 core ingredients, i.e., quercetin and berberine from CR; wogonin, baicalein, acacetin and beta-sitosterol from SR; and aloe-emodin, EUPATIN and (-)-catechin from RR (Fig. 3D). Quercetin had the most targets (39 targets), followed by wogonin (13 targets) and baicalein (6 targets; Fig. 3E), suggesting their key roles in anti-UC function.

\section{GO and KEGG pathway enrichment analyses}

To investigate the detailed functions of the above 45 hub targets, GO function and KEGG pathway enrichment analyses were carried out. In GO analysis, these targets were primary enriched in cellular components of nucleus, cytoplasm and extracellular space, and mainly involved in protein binding, enzyme binding and tanscription factor binding as molecular functions (Fig. 4A).

\section{(See figure on next page.)}

Fig. 2 SHD decreases C. albicans burden and alleviates systemic inflammation in UC mice. A C. albicans load in feces was examined by agar plating at days 7, 9, 11, 13, 15 and 17, respectively. B Serum $\beta$-glucan and $\mathbf{C}$ anti-Saccharomyces cerevisiae antibodies (ASCA) amounts were assessed by ELISA. D Serum TNF-a, E IL-1 $\beta, \mathbf{F} \| \mathrm{L}-6$ and $\mathbf{G} \| \mathrm{L}-10$ amounts were assessed by ELISA. Data are mean \pm SD. ${ }^{\#} P<0.05$, \#\# $P<0.01$ versus normal group; ${ }^{*} P<0.05,{ }^{* *} P<0.01$ versus Model group 
A

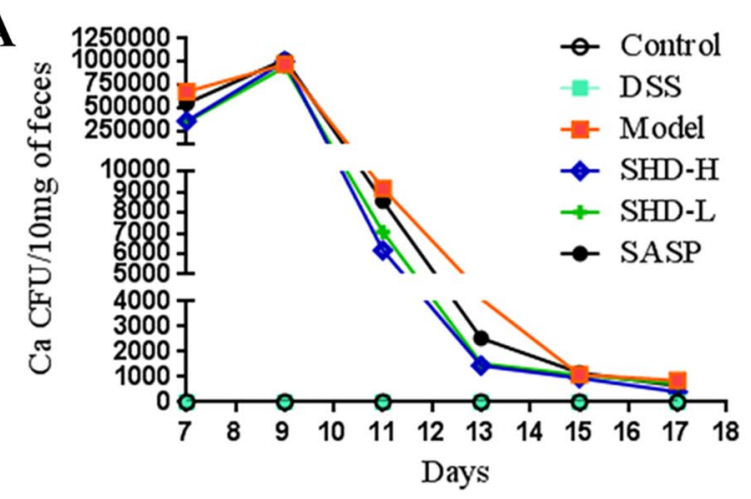

C

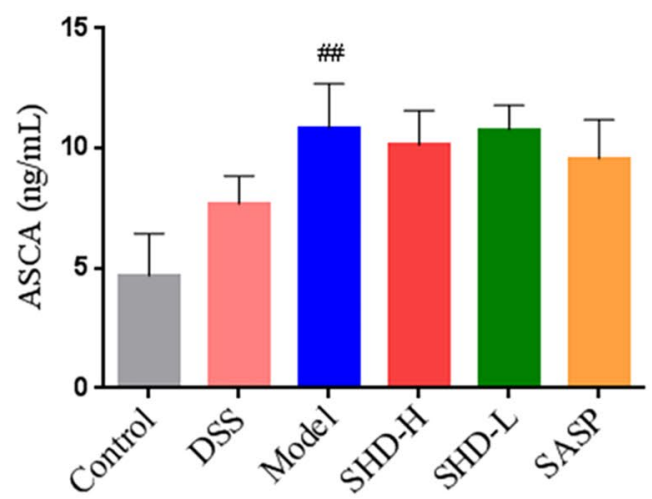

E

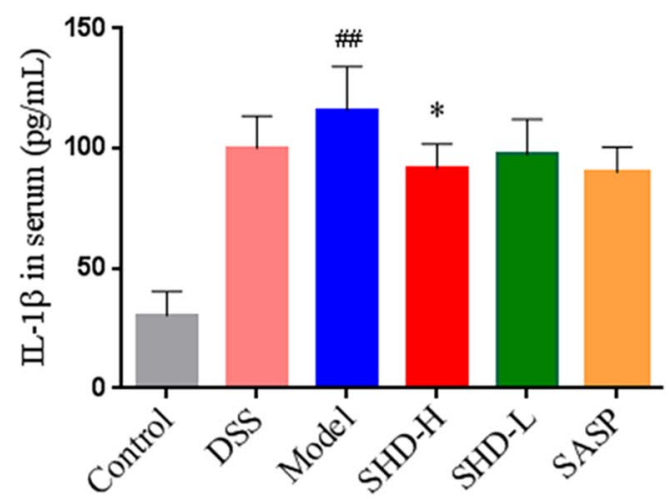

G

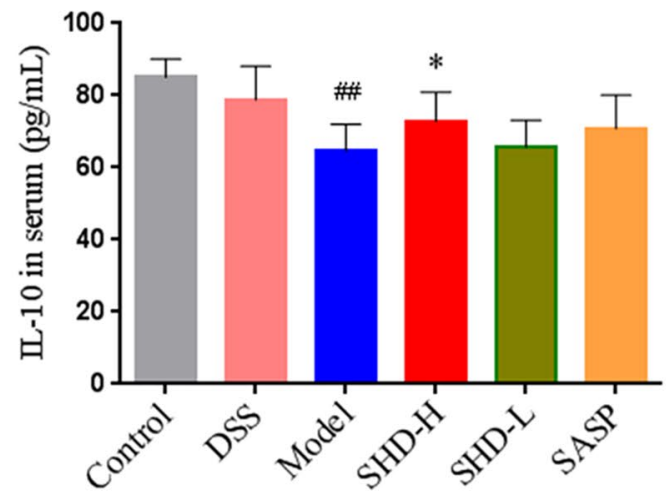

B

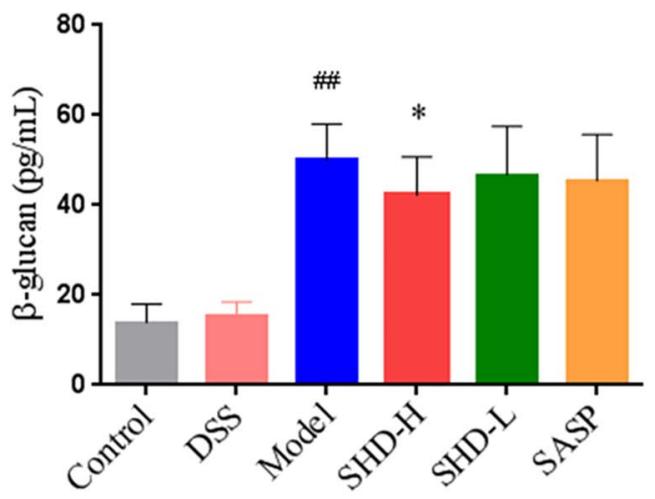

D

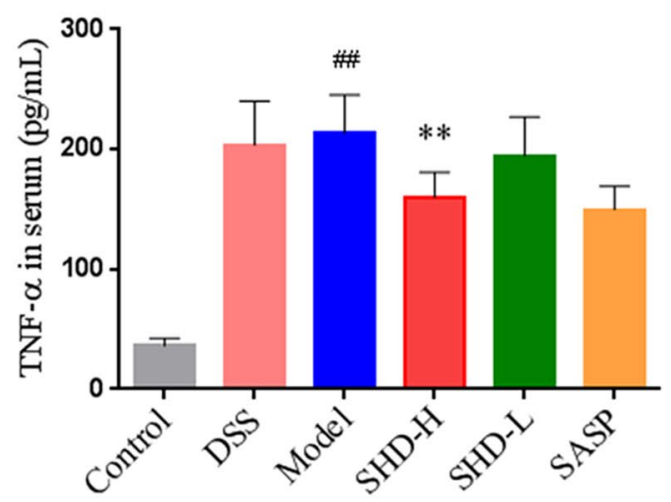

F

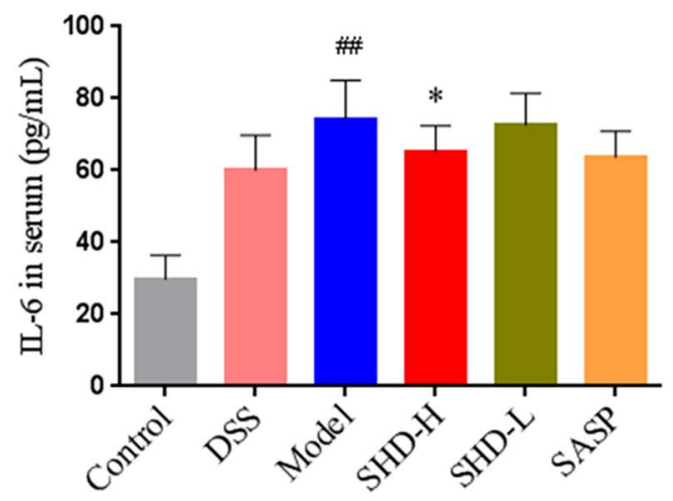

Fig. 2 (See legend on previous page.) 
Table 1 The potential active compounds and targets in SHD

\begin{tabular}{|c|c|c|c|c|}
\hline Drug & Molecule name & $\mathrm{OB}(\%)$ & $\mathrm{DL}$ & Target number \\
\hline CR1 & berberine & 36.86 & 0.78 & 17 \\
\hline$C R$ & Obacunone & 43.29 & 0.77 & 0 \\
\hline CR2 & berberrubine & 35.74 & 0.73 & 13 \\
\hline $\mathrm{CR}(\mathrm{B} 1)$ & epiberberine & 43.09 & 0.78 & 11 \\
\hline CR3 & (R)-Canadine & 55.37 & 0.77 & 31 \\
\hline CR4 & Berlambine & 36.68 & 0.82 & 20 \\
\hline CR5 & Corchoroside A_qt & 104.95 & 0.78 & 2 \\
\hline CR6 & Magnograndiolide & 63.71 & 0.19 & 4 \\
\hline$C R$ & Palmidin A & 35.36 & 0.65 & 0 \\
\hline CR7 & palmatine & 64.6 & 0.65 & 19 \\
\hline CR8 & quercetin & 46.43 & 0.28 & 154 \\
\hline CR(B2) & coptisine & 30.67 & 0.86 & 9 \\
\hline CR9 & Worenine & 45.83 & 0.87 & 7 \\
\hline$C R$ & Moupinamide & 86.71 & 0.26 & 0 \\
\hline SR1 & acacetin & 34.97 & 0.24 & 26 \\
\hline SR2 & wogonin & 30.68 & 0.23 & 45 \\
\hline SR3 & (2R)-7-hydroxy-5-methoxy-2-phenylchroman-4-one & 55.23 & 0.2 & 21 \\
\hline SR4 & baicalein & 33.52 & 0.21 & 37 \\
\hline SR & 5,8,2'-Trihydroxy-7-methoxyflavone & 37.01 & 0.27 & 0 \\
\hline SR5 & 5,7,2,5-tetrahydroxy-8,6-dimethoxyflavone & 33.82 & 0.45 & 13 \\
\hline SR6 & Carthamidin & 41.15 & 0.24 & 4 \\
\hline SR & 2,6,2',4'-tetrahydroxy-6'-methoxychaleone & 69.04 & 0.22 & 0 \\
\hline SR7 & Dihydrobaicalin_qt & 40.04 & 0.21 & 3 \\
\hline SR8 & Eriodyctiol (flavanone) & 41.35 & 0.24 & 8 \\
\hline SR9 & Salvigenin & 49.07 & 0.33 & 18 \\
\hline SR10 & 5,2',6'-Trihydroxy-7,8-dimethoxyflavone & 45.05 & 0.33 & 17 \\
\hline SR11 & $5,7,2^{\prime}, 6^{\prime}$-Tetrahydroxyflavone & 37.01 & 0.24 & 6 \\
\hline SR & dihydrooroxylin A & 38.72 & 0.23 & 0 \\
\hline SR12 & Skullcapflavone II & 69.51 & 0.44 & 21 \\
\hline SR13 & oroxylin a & 41.37 & 0.23 & 26 \\
\hline SR14 & Panicolin & 76.26 & 0.29 & 14 \\
\hline SR15 & 5,7,4'-Trihydroxy-8-methoxyflavone & 36.56 & 0.27 & 18 \\
\hline SR16 & NEOBAICALEIN & 104.34 & 0.44 & 22 \\
\hline SR17 & DIHYDROOROXYLIN & 66.06 & 0.23 & 11 \\
\hline $\operatorname{SR}(A)$ & beta-sitosterol & 36.91 & 0.75 & 38 \\
\hline SR18 & sitosterol & 36.91 & 0.75 & 3 \\
\hline SR19 & Norwogonin & 39.4 & 0.21 & 12 \\
\hline SR20 & 5,2'-Dihydroxy-6,7,8-trimethoxyflavone & 31.71 & 0.35 & 21 \\
\hline SR21 & ent-Epicatechin & 48.96 & 0.24 & 6 \\
\hline SR22 & Stigmasterol & 43.83 & 0.76 & 31 \\
\hline $\mathrm{SR}(\mathrm{B} 2)$ & coptisine & 30.67 & 0.86 & 9 \\
\hline SR23 & bis[(2S)-2-ethylhexyl] benzene-1,2-dicarboxylate & 43.59 & 0.35 & 1 \\
\hline SR & Supraene & 33.55 & 0.42 & 0 \\
\hline SR24 & Diop & 43.59 & 0.39 & 3 \\
\hline $\mathrm{SR}(\mathrm{B} 1)$ & Epiberberine & 43.09 & 0.78 & 11 \\
\hline SR25 & Moslosooflavone & 44.09 & 0.25 & 25 \\
\hline SR26 & 11,13-Eicosadienoic acid, methyl ester & 39.28 & 0.23 & 1 \\
\hline SR27 & 5,7,4'-trihydroxy-6-methoxyflavanone & 36.63 & 0.27 & 6 \\
\hline SR28 & 5,7,4'-trihydroxy-8-methoxyflavanone & 74.24 & 0.26 & 6 \\
\hline
\end{tabular}


Table 1 (continued)

\begin{tabular}{|c|c|c|c|c|}
\hline Drug & Molecule name & OB (\%) & $\mathrm{DL}$ & Target number \\
\hline SR29 & rivularin & 37.94 & 0.37 & 22 \\
\hline RR1 & EUPATIN & 50.8 & 0.41 & 16 \\
\hline $\mathrm{RR}$ & Mutatochrome & 48.64 & 0.61 & 0 \\
\hline $\mathrm{RR} 2$ & Physciondiglucoside & 41.65 & 0.63 & 1 \\
\hline $\mathrm{RR}$ & Procyanidin B-5,3'-O-gallate & 31.99 & 0.32 & 0 \\
\hline RR3 & rhein & 47.07 & 0.28 & 7 \\
\hline $\mathrm{RR}$ & Sennoside E_qt & 50.69 & 0.61 & 0 \\
\hline RR4 & Torachrysone-8-O-beta-D-(6'-oxayl)-glucoside & 43.02 & 0.74 & 1 \\
\hline RR5 & Toralactone & 46.46 & 0.24 & 9 \\
\hline RR6 & Emodin-1-O-beta-D-glucopyranoside & 44.81 & 0.8 & 1 \\
\hline $\mathrm{RR}$ & Sennoside D_qt & 61.06 & 0.61 & 0 \\
\hline RR7 & Daucosterol_qt & 35.89 & 0.7 & 2 \\
\hline $\mathrm{RR}$ & palmidin A & 32.45 & 0.65 & 0 \\
\hline$R R(A)$ & beta-sitosterol & 36.91 & 0.75 & 38 \\
\hline RR8 & aloe-emodin & 83.38 & 0.24 & 24 \\
\hline $\mathrm{RR}$ & gallic acid-3-O-(6'-O-galloyl)-glucoside & 30.25 & 0.67 & 0 \\
\hline RR9 & $(-)$-catechin & 49.68 & 0.24 & 11 \\
\hline
\end{tabular}

Regarding biological processes, these core targets were primary involved in positive regulation of transcription, negative regulation of apoptosis, response to drugs, angiogenesis and inflammatory response (Fig. 4A).

KEGG pathway analysis showed the hub genes highly participated in pathways related to cancer (25 genes), PI3K-Akt signaling (17 genes), TNF signaling (16 genes), HIF-1 signaling (13 genes), MAPK signaling (13 genes) and Toll-like receptor signaling (12 genes), indicating the underlying molecular mechanisms of SHD in UC treatment (Fig. 4B).

\section{Identification of differentially expressed genes post-SHD treatment in mice with C. albicans-associated colitis}

Colonic tissue transcriptomics analysis was conducted for elucidating the functional genes affected by SHD. Totally 9 samples in three groups (i.e., Control, Model and SHD groups, three samples per group) were tested, and an average yield of $6.63 \mathrm{G}$ data per sample was obtained. Totally 18,240 genes were found, with 17,241 in the Control group, 17,624 in the Model group and 17,522 in the SHD group, with 16,722 genes shared among these three groups (Additional file 1: Figure S3). Compared with the Model group, 370 genes were differentially expressed (DEGs) in the SHD group (Fig. 5A, B), including 151 upregulated and 219 downregulated (Fig. 5C).

\section{Functions of DEGs}

GO analysis revealed DEGs were primarily involved in transmembrane transport (26 genes), immune system process (23 genes), response to a bacterium (22 genes), innate immune response (21 genes) and innate immune response in mucosa (16 genes) (Fig. 5D, Additional file 1: Figure S4).

KEGG pathway analysis revealed DEGs were basically enriched in inflammatory and immune responserelated signaling pathways, including PI3K-Akt signaling, NOD-like receptor signaling, Cytokine-cytokine receptor interaction, Inflammatory mediator regulation of TRP channels and Arachidonic acid metabolism (Fig. 5E). Significantly, genes enriched in the PI3K-Akt and NOD-like receptor pathways were downregulated in the colon tissue of SHD treated mice, indicating SHD may exert antifungal-UC effects through these targets and pathways.

\section{SHD attenuates $C$. albicans-associated colitis via the TLR4-NF-KB and PI3K-Akt pathways}

For further validating SHD targets in C. albicans-associated colitis, key TLR4-NF-kB and PI3K-Akt pathway effectors were examined. TLR4 and IL- $1 \beta$ amounts were overtly increased in the Model group in comparison with the Control group $(P<0.05$; Figs. 6A, 7A, B). Although NF-kB, PI3K and Akt amounts had no differences between the Model and Control groups, $\mathrm{p}-\mathrm{NF}-\mathrm{k} \mathrm{B}$, $\mathrm{p}-\mathrm{PI} 3 \mathrm{~K}$ and $\mathrm{p}-\mathrm{Akt}$ levels were much higher than those of the Control group $(P<0.05$ or 0.01 ; Figs. $6 \mathrm{~A}, \mathrm{~B}, 7 \mathrm{~A}, \mathrm{~B})$. Aberrant expression of TLR $4, \mathrm{IL}-1 \beta, \mathrm{p}-\mathrm{NF}-\mathrm{kB}, \mathrm{p}-\mathrm{PI} 3 \mathrm{~K}$ and $\mathrm{p}-\mathrm{Akt}$ was reversed by SHD, which was consistent with the above findings in systems pharmacology and transcriptomics $(P<0.05$; Figs. 6A, B, 7A, B). 


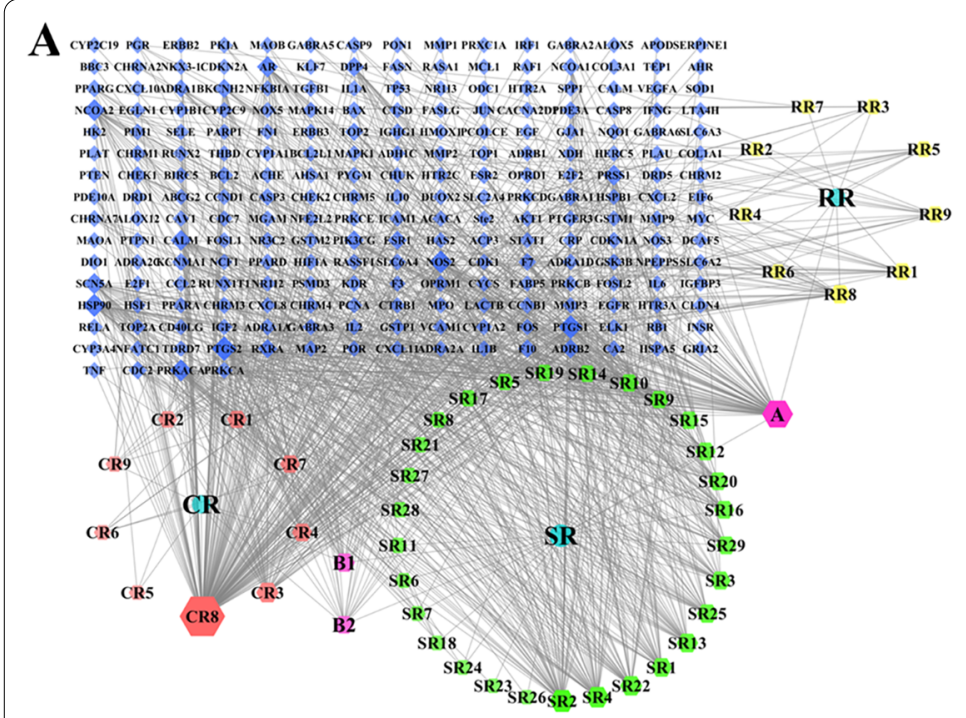

\section{B SHD}

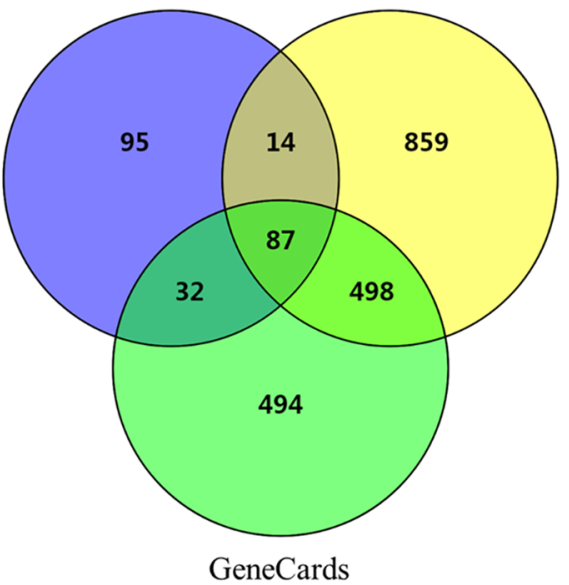

$\mathbf{C}$

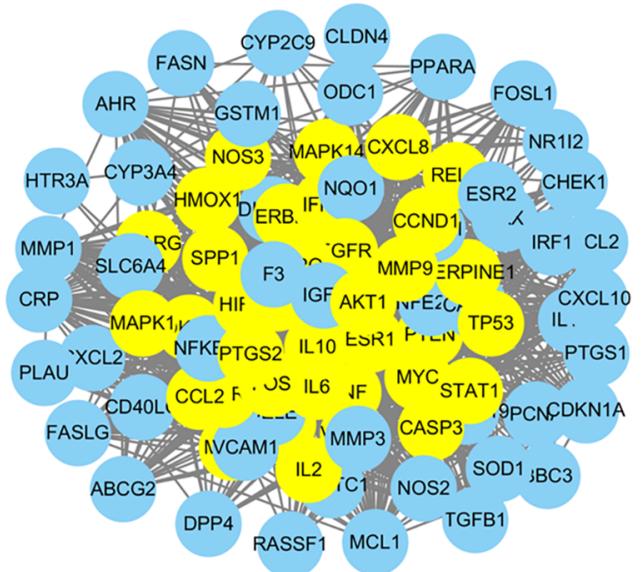

$\mathrm{DC} \geq 37$

$\mathrm{CC} \geq 0.64$

$\mathrm{BC} \geq 0.003$
D

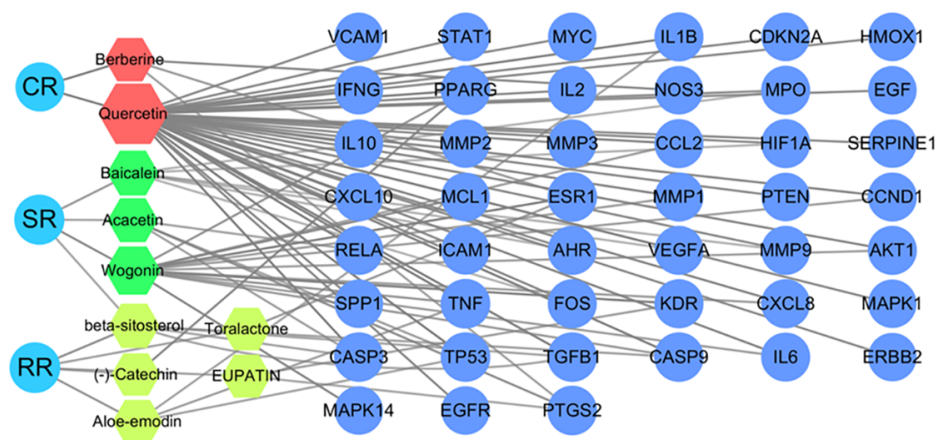

Fig. 3 Core constituents and hub targets of SHD in UC. A Compound-Target network of SHD. Pink nodes represent CR, green nodes represent $S R$, yellow nodes represent RR, and blue nodes represent the targets. The purple node A represents a compound shared by SR and RR; the purple nodes B1 and B2 represent compounds shared by CR and SR. B Venn diagram of targets shared by SHD and UC. C The topological screening for the PPI network. D Network of core constituents and targets. $\mathbf{E}$ The numbers of targets for the 9 core substituents

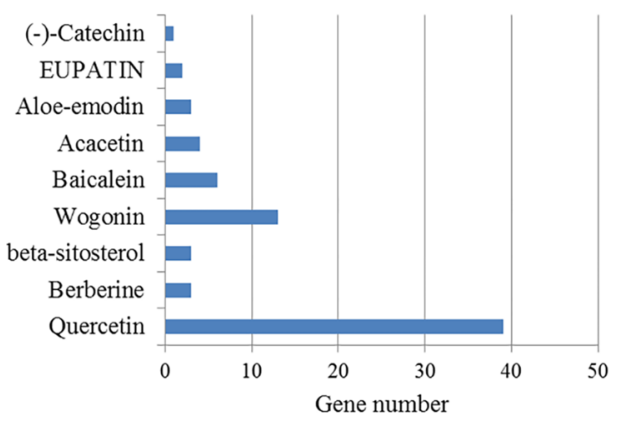

\section{$\mathbf{E}$}



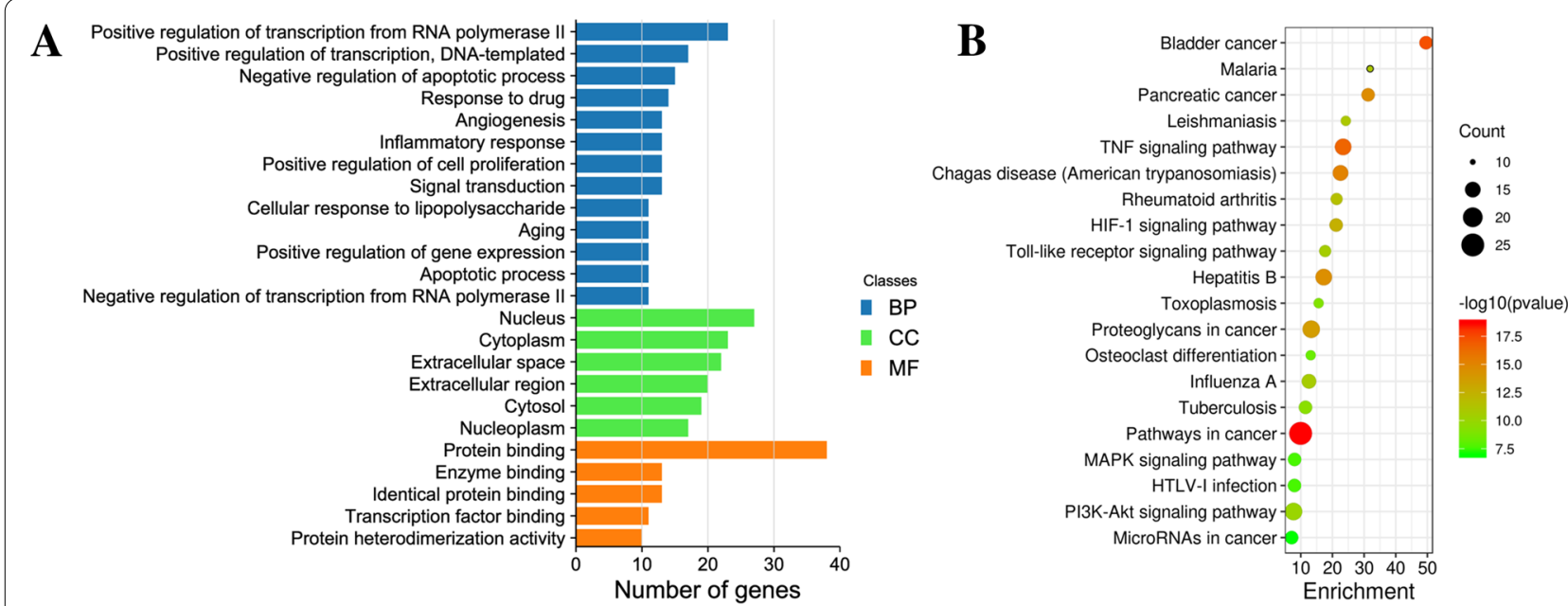

Fig. 4 GO function and KEGG pathway analyses of the hub genes. A Top 15 biological processes (BP), 6 cellular components (CC) and 5 molecular functions. B Top 20 KEGG pathways

\section{Discussion}

Recently, gut fungi dysbiosis has been recognized as an important factor involved in UC pathogenesis [5, 28]. As one of the predominant fungi related to IBD, C. albicans is not commensal in the mouse gut, which differs from humans; therefore, DSS induced colitis with C. albicans infection may more adequately mimic the human disease $[12,29]$. In this study, we established this model as previously described, with minor modifications [9]. Briefly, a $C$. albicans-colonized UC model was established via exposure to $3.0 \%$ DSS in drinking water for 7 days, followed by administration of $1.0 \times 10^{8} \mathrm{C}$. albicans live cells $/ \mathrm{mL}$ by continuous gavage for 4 days. We found that C. albicans aggravated DSS-induced colitis, with higher DAI, histological score and serum levels of inflammatory factors versus DSS alone group. Therefore, this model could resemble the status of IBD with $C$. albicans overgrowth in humans.

Traditional Chinese medicine has been broadly applied for treating UC in China for a long time due to its safety and efficacy in UC. Several classical prescriptions, including Shaoyao decoction [30], Huangqing decoction [31] and Huang-Lian-Jie-Du decoction [32], were verified to exhibit therapeutic effects in UC. These effective formulas perform several common functions such as heat-clearing, dampness-drying and detoxification, which are also carried out by SHD. However, few studies have revealed the anti-UC and anti-inflammatory functions of SHD, and whether SHD enema is effective against $\mathrm{UC}$ with $C$. albicans colonization remains unknown. Here, we found that SHD could effectively ameliorate UC symptoms in this animal model. SHD administration decreased body weight loss, DAI score and colon length shortening. Moreover, SHD reduced local and systemic $C$. albicans burdens, inhibited mucosal and submucosal damage, and relived inflammatory response, which was consistent with previous study [24]. Taken together, SHD enema may be a potential strategy to overcome $\mathrm{UC}$ with $C$. albicans dysbiosis.

The complex composition and multiple action patterns of TCM make it hard to understand its detailed therapeutic mechanisms at the molecular level [33]. Network pharmacology, a new systems approach for exploring new active ingredients and potential action mechanisms for TCM preparations [34], has been widely used in pharmacological research of TCM against UC [35-38]. Using this method, 9 core ingredient and 45 related key targets were identified, and quercetin, wogonin and baicalein were found to be probably the key active compounds of SHD in UC therapy. GO and KEGG pathway analyses revealed these 45 hub genes were mostly involved in immune and inflammatory responses, with roles in the PI3K-Akt, TNF, HIF-1, MAPK and Toll-like receptor pathways.

Transcriptomics is a high-throughput technique to observe mRNAs with differential expression in different tissues and time points in organisms, playing a major role in the study of drug action mechanism [39, 40]. In this study, 370 differentially expressed genes, including 151 upregulated and 219 downregulated, were screened. Function enrichment results for these DEGs partly 


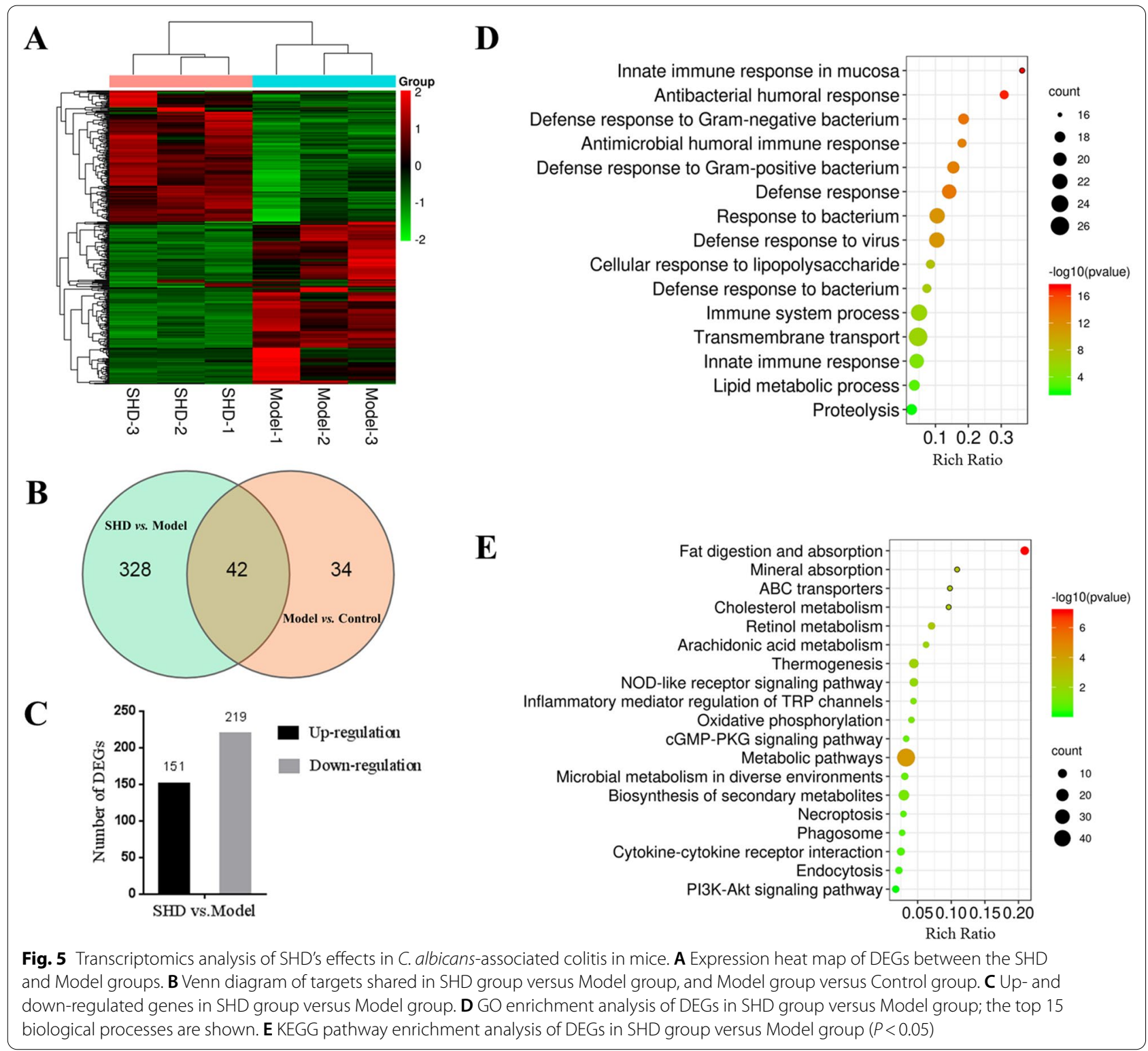

coincided with those of network pharmacology. GO function analysis revealed that these DEGs were primary involved in biological process, immune system process, innate immune response and innate immune response in mucosa. KEGG analysis showed these DEGs were basically enriched in PI3K-Akt and NOD-like receptor pathways. Taken together, these results indicate the relative accuracy of our network in predicting SHD targets, and support the reliability of transcriptome sequencing results.

The Toll-like receptor signaling pathway, an important signaling pathway that detects and removes pathogens, is involved in UC pathogenesis and targeted by many
Chinese medicine preparations against ulcerative colitis [41-43]. The transcriptome data in this study suggested that Toll-like receptor signaling-related genes were downregulated after SHD treatment. Indeed, TLR4, NF- $\mathrm{kB}$ and IL- $1 \beta$ were downregulated in the SHD group in comparison with the Model group, indicating that SHD might play an anti-UC role by inhibiting the TLR4/ NF- $\mathrm{kB}$ signal pathway.

PI3K-Akt signaling represents another important pathway contributing to the pathogenesis of ulcerative colitis [44]. Huang et al. found that wortmannin (a PI3K inhibitor) reduces p-Akt and TNF- $\alpha$ amounts 


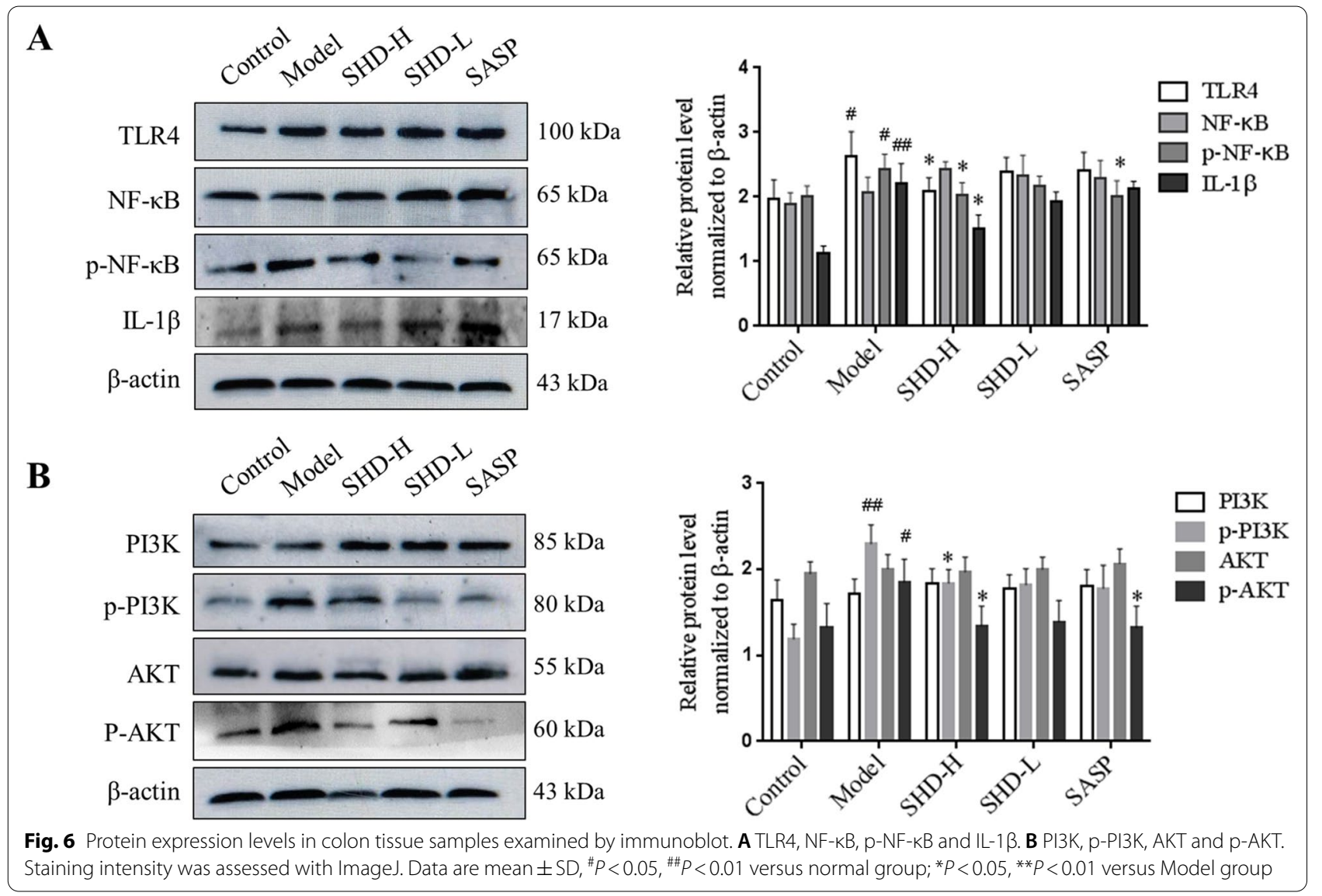

in colon tissue samples from DSS-treated mice, and significantly alleviates inflammation in colitis [45]. Some TCMs or natural compounds exert their antiUC effects via PI3K-Akt signaling. For example, oxymatrine markedly ameliorates UC via anti-inflammatory and pro-apoptotic mechanisms, suppressing Th1 and Th17 cell differentiation through PI3K-AKT signaling [46]. Baicalin alleviates the severity of colon inflammation by blocking the TLR4/NF-kB-p65/ IL-6 signaling pathway [47]. We found that PI3K and Akt phosphorylation levels in the SHD group were decreased significantly, suggesting that SHD may inhibit UC with Candida albicans colonization by suppressing the PI3K-AKT pathway.

\section{Conclusion}

Taken together, network pharmacology and transcriptomics data suggested SHD could alleviate UC with $C$. albicans colonization via synergistic effects of many constituents and targets.

We propose Sanhuang decoction enema may function as an effective anti-UC approach by reducing the additional impact of $C$. albicans on the progression of DSS-induced colitis, decreasing fecal fungal burden and lowering systemic inflammation mainly via the TLR4/ NF-kB and PI3K-Akt pathways. The present work uncovered the mechanism of SHD in UC with $C$. albicans dysbiosis and provided a scientific basis for a rational application of traditional Chinese medicine. 


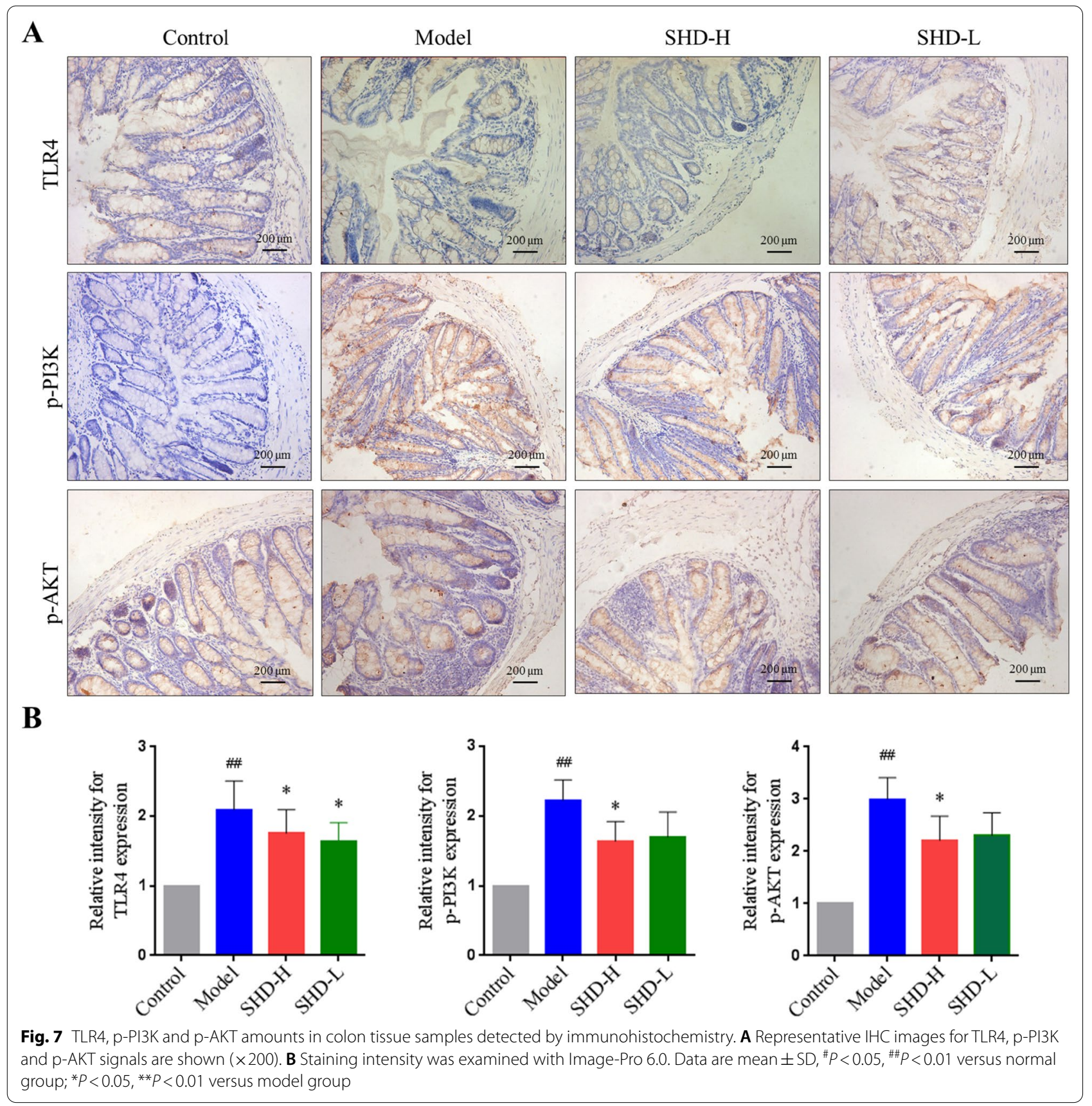

\section{Abbreviations}

BC: Betweenness centrality; CC: Closeness centrality; CR: Coptidis Rhizoma; DAl: Disease activity index; DC: Degree centrality; DEGs: Differentially expressed genes; DL: Drug-like property; GI: Gastrointestinal; GO: Gene ontology; H\&E: Hematoxylin and eosin; KEGG: Kyoto encyclopedia of genes and genomes; LC-MS: Liquid chromatography-mass spectrometry; OB: Oral bioavailability; PPI: Protein-protein interaction; RR: Radix Rhei Et Rhizome; SHD: San-Huang decoction; SPF: Specific pathogen-free; SR: Scutellariae radix; UC: Ulcerative colitis.

\section{Supplementary Information}

The online version contains supplementary material available at https://doi. org/10.1186/s13020-021-00487-2.
Additional file 1: Figure S1. LC-MS chromatograms of main ingredients in SHD. Figure S2. Representative photographs of colon samples. Figure S3. Venn diagram of targets shared in the Control, Model and SHD groups. Figure S4. GO analysis of DEGs in SHD group versus Model group. (A) Top 15 molecular functions. (B) Top 14 cellular components.

Additional file 2: Table S1. The contents of main ingredients in SHD.

Acknowledgements

Not applicable. 


\section{Authors' contributions}

KM and CW designed the experiments; ZH, XT and JS performed the experiments; TW and YG analyzed the data and validated the experiments; ZH and KM drafted the manuscript. All authors read and approved the final version of the manuscript.

\section{Funding}

The current project was funded by the National Natural Science Foundation of China (81573725 and 81774034), the Outstanding Youth Project of Anhui Institution of Higher Education (gxyq2019030), the Natural Science Foundation of Anhui Institution of Higher Education (KJ2019A0476), and the Discipline Construction Key Program of Anhui University of Chinese Medicine (DC18100042)

\section{Availability of data and materials}

The data set supporting the results of this article are included within the article and Additional files.

\section{Declarations}

\section{Ethics approval and consent to participate}

Experiments involving animals had approval from the Animal Ethics Committee of Anhui University of Chinese Medicine.

\section{Consent for publication}

Not applicable.

\section{Competing interests}

The authors declare that they have no conflict of interest.

\section{Author details}

${ }^{1}$ College of Integrated Chinese and Western Medicine, College of Life Science, Anhui University of Chinese Medicine, Hefei 230012, China. ${ }^{2}$ Institute of Integrated Chinese and Western Medicine, Anhui Academy of Chinese Medicine, Hefei 230012, China. ${ }^{3}$ Anhui Provincial Key Laboratory of New Manufacturing Technology for Chinese Medicinal Decoction Pieces, Anhui University of Chinese Medicine, Hefei 230012, China. ${ }^{4}$ Key Laboratory of Xin'An Medicine, Ministry of Education, Anhui Academy of Chinese Medicine, Hefei 230012, China.

Received: 21 April 2021 Accepted: 2 August 2021

Published online: 10 August 2021

\section{References}

1. Selvaratnam S, Gullino S, Shim L, Lee E, Lee A, Paramsothy S, Leong RW. Epidemiology of inflammatory bowel disease in South America: a systematic review. World J Gastroenterol. 2019;25(47):6866-75.

2. Hou JK, El-Serag H, Thirumurthi S. Distribution and manifestations of inflammatory bowel disease in Asians, Hispanics, and African Americans: a systematic review. Am J Gastroenterol. 2009;104(8):2100-9.

3. Kaplan GG, Ng SC. Globalisation of inflammatory bowel disease: perspectives from the evolution of inflammatory bowel disease in the UK and China. The Lancet Gastroenterol Hepatol. 2016;1(4):307-16.

4. Cui G, Yuan A. A systematic review of epidemiology and risk factors associated with Chinese inflammatory bowel disease. Front Med. 2018:5:183.

5. Sokol H, Leducq V, Aschard H, Pham HP, Jegou S, Landman C, Cohen D, Liguori G, Bourrier A, Nion-Larmurier l, et al. Fungal microbiota dysbiosis in IBD. Gut. 2017;66(6):1039-48.

6. Ge Y, Pan M, Zhang C, Wang C, Ma K, Yan G, Wang T, Wu D, Shao J. Paeonol alleviates dextran sodium sulfate induced colitis involving Candida albicans-associated dysbiosis. Med Mycol. 2021;59(4):335-44.

7. Jawhara S, Thuru X, Standaert-Vitse A, Jouault T, Mordon S, Sendid B, Desreumaux P, Poulain D. Colonization of mice by Candida albicans is promoted by chemically induced colitis and augments inflammatory responses through galectin-3. J Infect Dis. 2008;197(7):972-80.
8. Zwolinska-Wcislo M, Brzozowski T, Budak A, Kwiecien S, Sliwowski Z, Drozdowicz D, Trojanowska D, Rudnicka-Sosin L, Mach T, Konturek SJ, et al. Effect of Candida colonization on human ulcerative colitis and the healing of inflammatory changes of the colon in the experimental model of colitis ulcerosa. J Physiol Pharmacol: Off J Polish Physiol Soc. 2009;60(1):107-18.

9. Panpetch W, Hiengrach P, Nilgate S, Tumwasorn S, Somboonna N, Wilantho A, Chatthanathon P, Prueksapanich P, Leelahavanichkul A. Additional Candida albicans administration enhances the severity of dextran sulfate solution induced colitis mouse model through leaky gut-enhanced systemic inflammation and gut-dysbiosis but attenuated by Lactobacillus rhamnosus L34. Gut microbes. 2020;11(3):465-80.

10. Zhang SL, Wang SN, Miao CY. Influence of microbiota on intestinal immune system in ulcerative colitis and its intervention. Front Immunol. 2017:8:1674.

11. Trojanowska D, Zwolinska-Wcislo M, Tokarczyk M, Kosowski K, Mach T, Budak A. The role of Candida in inflammatory bowel disease. Estimation of transmission of C. albicans fungi in gastrointestinal tract based on genetic affinity between strains. Med Sci Monitor Int Med J Exp Clin Res. 2010;16(10):C451-457.

12. Panpetch W, Somboonna N, Bulan DE, Issara-Amphorn J, Worasilchai N, Finkelman M, Chindamporn A, Palaga T, Tumwasorn S, Leelahavanichkul A. Gastrointestinal colonization of Candida albicans increases serum (1->3)-beta-D-Glucan, without Candidemia, and Worsens Cecal ligation and puncture sepsis in murine model. Shock. 2018;49(1):62-70.

13. Choteau L, Vancraeyneste $H$, Le Roy D, Dubuquoy L, Romani L, Jouault T, Poulain D, Sendid B, Calandra T, Roger T, et al. Role of TLR1, TLR2 and TLR6 in the modulation of intestinal inflammation and Candida albicans elimination. Gut pathogens. 2017;9:9.

14. Lee JC, Tseng CK, Wu SF, Chang FR, Chiu CC, Wu YC. San-Huang-Xie-XinTang extract suppresses hepatitis $C$ virus replication and virus-induced cyclooxygenase-2 expression. J Viral Hepatitis. 2011;18(7):e315-324.

15. Liou SF, Ke HJ, Hsu JH, Liang JC, Lin HH, Chen IJ, Yeh JL. San-HuangXie-Xin-Tang prevents rat hearts from Ischemia/Reperfusion-induced apoptosis through eNOS and MAPK pathways. Evid-Based Complement Altern Med eCAM. 2011;2011:915051.

16. Shih YT, Wu DC, Liu CM, Yang YC, Chen IJ, Lo YC. San-Huang-Xie-Xin-Tang inhibits Helicobacter pylori-induced inflammation in human gastric epithelial AGS cells. J Ethnopharmacol. 2007;112(3):537-44.

17. Liao Z, Xie Y, Zhou B, Zou B, Xiao D, Liu W, Cai Y, Liu D, Liao Q, Xie Z. Berberine ameliorates colonic damage accompanied with the modulation of dysfunctional bacteria and functions in ulcerative colitis rats. Appl Microbiol Biotechnol. 2020;104(4):1737-49.

18. Deng J, Wu Z, Zhao Z, Wu C, Yuan M, Su Z, Wang Y, Wang Z. Berberineloaded nanostructured lipid carriers enhance the treatment of ulcerative colitis. Int J Nanomed. 2020;15:3937-51.

19. Zoric N, Kosalec I, Tomic S, Bobnjaric I, Jug M, Vlainic T, Vlainic J. Membrane of Candida albicans as a target of berberine. BMC Complement Altern Med. 2017;17(1):268.

20. Wang T, Shi G, Shao J, Wu D, Yan Y, Zhang M, Cui Y, Wang C. In vitro antifungal activity of baicalin against Candida albicans biofilms via apoptotic induction. Microb Pathog. 2015;87:21-9.

21. Yang S, Fu Y, Wu X, Zhou Z, Xu J, Zeng X, Kuang N, Zeng Y. Baicalin prevents Candida albicans infections via increasing its apoptosis rate. Biochem Biophys Res Commun. 2014;451(1):36-41.

22. Liang S, Deng X, Lei L, Zheng Y, Ai J, Chen L, Xiong H, Mei Z, Cheng YC, Ren $Y$. The comparative study of the therapeutic effects and mechanism of baicalin, baicalein, and their combination on ulcerative colitis rat. Front Pharmacol. 2019;10:1466.

23. Luo S, Deng X, Liu Q, Pan Z, Zhao Z, Zhou L, Luo X. Emodin ameliorates ulcerative colitis by the flagellin-TLR5 dependent pathway in mice. Int Immunopharmacol. 2018;59:269-75.

24. Wang S, Zhou T, Zhai JP, Wang LH, Chen J. Effects of modified Sanhuang decoction () enema on serum tumor necrosis factor-alpha and colonic mucosa interleukin-1 beta, interleukin-6 levels in ulcerative colitis rats. Chin J Integr Med. 2014;20(11):865-9.

25. Han XH, Zhong J, Guo JY, Shi R, Wang XH, Wang CH, Wang K, Du GL, Shen $\mathrm{YH}, \mathrm{Ma}$ YM. Relationships between pharmacokinetics and efficacy of 
Xie-xin decoction in rats with experimental ulcerative colitis. J Ethnopharmacol. 2013;148(1):182-9.

26. Li J, Zhang J, Guo H, Yang S, Fan W, Ye N, Tian Z, Yu T, Ai G, Shen Z, et al. Critical role of alternative M2 skewing in miR-155 deletion-mediated protection of colitis. Front Immunol. 2018;9:904.

27. Li S, Chen YT, Ding QY, Dai JY, Duan XC, Hu YJ, et al. Network pharmacology evaluation method guidance-Draft. World J Tradit Chin Med. 2021;7(1):146-54.

28. Sovran B, Planchais J, Jegou S, Straube M, Lamas B, Natividad JM, Agus A, Dupraz L, Glodt J, Da Costa G, et al. Enterobacteriaceae are essential for the modulation of colitis severity by fungi. Microbiome. 2018;6(1):152.

29. Panpetch W, Somboonna N, Bulan DE, Issara-Amphorn J, Finkelman M, Worasilchai N, Chindamporn A, Palaga T, Tumwasorn S, Leelahavanichkul A. Oral administration of live- or heat-killed Candida albicans worsened cecal ligation and puncture sepsis in a murine model possibly due to an increased serum (1->3)-beta-D-glucan. PLoS ONE. 2017;12(7):0181439.

30. Zhong Y, Zheng XB, Ye H, Guo M, Wu Q, Zou Y, Chi HG, Zhu YZ. Effect of Shaoyao Tang on ulcerative colitis in rats via regulation of TLR4/NFkappaB signal pathway. Zhongguo Zhong Yao Za Zhi. 2019;44(7):1450-6.

31. Li MY, Li MX, Xu N, Li ZH, Zhang YM, Gan YX, Luo HJ, Zhou CL, Liu YH, Su $Z R$, et al. Effects of Huangqin Decoction on ulcerative colitis by targeting estrogen receptor alpha and ameliorating endothelial dysfunction based on system pharmacology. J Ethnopharmacol. 2021;271:113886.

32. Yuan Z, Yang L, Zhang X, Ji P, Hua Y, Wei Y. Huang-Lian-Jie-Du decoction ameliorates acute ulcerative colitis in mice via regulating NF-kappaB and Nrf2 signaling pathways and enhancing intestinal barrier function. Front Pharmacol. 2019:10:1354

33. Wang J, Liu R, Liu B, Yang Y, Xie J, Zhu N. Systems pharmacology-based strategy to screen new adjuvant for hepatitis B vaccine from Traditional Chinese Medicine Ophiocordyceps sinensis. Sci Rep. 2017;7:44788.

34. Cheng L, Pan GF, Zhang XD, Wang JL, Wang WD, Zhang JY, Wang H, Liang RX, Sun XB. Yindanxinnaotong, a Chinese compound medicine, synergistically attenuates atherosclerosis progress. Sci Rep. 2015;5:12333.

35. Yu Y, Zhang G, Han T, Huang H. Analysis of the pharmacological mechanism of Banxia Xiexin decoction in treating depression and ulcerative colitis based on a biological network module. BMC Complement Med Ther. 2020;20(1):199

36. Gu S, Xue Y, Gao Y, Shen S, Zhang Y, Chen K, Xue S, Pan J, Tang Y, Zhu $\mathrm{H}$, et al. Mechanisms of indigo naturalis on treating ulcerative colitis explored by GEO gene chips combined with network pharmacology and molecular docking. Sci Rep. 2020;10(1):15204.

37. Yang H, Li Y, Shen S, Gan D, Han C, Wu J, Wang Z. Network pharmacologybased investigation into the mechanisms of quyushengxin formula for the treatment of ulcerative colitis. Evid-Based Complement Altern Med: eCAM. 2019;2019:7870424.

38. Xu L, Zhang J, Wang Y, Zhang Z, Wang F, Tang X. Uncovering the mechanism of Ge-Gen-Qin-Lian decoction for treating ulcerative colitis based on network pharmacology and molecular docking verification. Biosci Rep 2021

39. Taman H, Fenton CG, Hensel IV, Anderssen E, Florholmen J, Paulssen RH. Transcriptomic landscape of treatment-naive ulcerative colitis. J Crohns Colitis. 2018:12(3):327-36.

40. Cheng F, Li Q, Wang J, Zeng F, Wang K, Zhang Y. Identification of differential intestinal mucosa transcriptomic biomarkers for ulcerative colitis by bioinformatics analysis. Dis Markers. 2020;2020:8876565.

41. Shi YJ, Hu SJ, Zhao QQ, Liu XS, Liu C, Wang H. Toll-like receptor 4 (TLR4) deficiency aggravates dextran sulfate sodium (DSS)-induced intestinal injury by down-regulating IL6, CCL2 and CSF3. Ann Trans Med. 2019; $7(23): 713$

42. Chen YX, Zhang XQ, Yu CG, Huang SL, Xie Y, Dou XT, Liu WJ, Zou XP. Artesunate exerts protective effects against ulcerative colitis via suppressing Tolllike receptor 4 and its downstream nuclear factorkappaB signaling pathways. Mol Med Rep. 2019;20(2):1321-32

43. Bing X, Xuelei L, Wanwei D, Linlang L, Keyan C. EGCG maintains Th1/ Th2 balance and mitigates ulcerative colitis induced by dextran sulfate sodium through TLR4/MyD88/NF-kappaB signaling pathway in rats. Can 」 Gastroenterol Hepatol. 2017;2017:3057268.

44. Wang X, Li D, Zhang Y, Wu S, Tang F. Costus root granules improve ulcerative colitis through regulation of TGF-beta mediation of the PI3K/AKT signaling pathway. Exp Ther Med. 2018;15(5):4477-84.

45. Huang XL, XU J, Zhang XH, Qiu BY, Peng L, Zhang M, Gan HT. PI3K/Akt signaling pathway is involved in the pathogenesis of ulcerative colitis. Inflamm Res: Off J Eur Histamine Res Soc [et al]. 2011;60(8):727-34.

46. Chen Q, Duan X, Fan H, Xu M, Tang Q, Zhang L, Shou Z, Liu X, Zuo D, Yang $J$, et al. Oxymatrine protects against DSS-induced colitis via inhibiting the PI3K/AKT signaling pathway. Int Immunopharmacol. 2017:53:149-57.

47. Feng J, Guo C, Zhu Y, Pang L, Yang Z, Zou Y, Zheng X. Baicalin down regulates the expression of TLR4 and NFkB-p65 in colon tissue in mice with colitis induced by dextran sulfate sodium. Int J Clin Exp Med. 2014;7(11):4063-72.

\section{Publisher's Note}

Springer Nature remains neutral with regard to jurisdictional claims in published maps and institutional affiliations.
Ready to submit your research? Choose BMC and benefit from:

- fast, convenient online submission

- thorough peer review by experienced researchers in your field

- rapid publication on acceptance

- support for research data, including large and complex data types

- gold Open Access which fosters wider collaboration and increased citations

- maximum visibility for your research: over $100 \mathrm{M}$ website views per year

At BMC, research is always in progress.

Learn more biomedcentral.com/submissions 